\title{
Compliance of the Web-based Distance Training and Consultancy on Individual's Treatment having Suffered Myocardial Infarction and its Effects on Well-being
}

\author{
Özlem Dogu ${ }^{1}$ and Hatice Kaya ${ }^{2}$
}

\begin{abstract}
Objective: To determine the compliance of the web-based remote training and counselling, required by the individuals suffering from myocardial infarction (MI), for their treatment and its effects on the functionality and well-being of the individual with some parameters determined by means of virtual platforms and information technologies.

Study Design: An experimental study.

Place and Duration of Study: Two hospitals in Sakarya, Turkey, from 2015 to 2016.

Methodology: The study population included individuals being treated due to acute $\mathrm{MI}$ in the hospital. One hundred and twenty individuals were divided into two groups to receive intervention $(n=60)$ and control group $(n=60)$. The data have been collected via Patient Information Form, The Myocardial Infarction Dimensional Assessment Scale (MIDAS) and Patient Follow-up Form.

Results: The test and control groups' demographic data were homogenously distributed. At the discharge, the MIDAS total score average was 30.0 for the control group and 26.43 for the test group. These values were determined as 28.57 for the control group and 13.57 for the test group at 3 months $(p<0.001)$.

Conclusion: Web-based remote training and counselling prepared the individuals after myocardial infarction to the treatment and their well-being in a positive way.
\end{abstract}

Key Words: Counselling, Patient training, Well-being, Myocardial infarction, Web-based remote training, Compliance to treatment.

\section{INTRODUCTION}

Myocardial infarction (MI) has the highest incidence and mortality rate among cardiovascular diseases (CVD). Mortality in $\mathrm{Ml}$ is usually seen within the first three months after the discharge. It decreases with the management of risk factors resulted by health behaviours and the compliance with treatment after discharge. The only way to achieve behaviour change is to raise awareness and educate the individual. ${ }^{1-4}$ Zahid et al. has shown that people with low knowledge score are at a greater risk of developing $\mathrm{MI}(\mathrm{OR}=3.73)$. They emphasise that counselling and training can help to manage as well as prevent heart disease by imparting knowledge about MI. 5

Cardiac rehabilitation is recommended after MI. However, it is not possible for every individual to benefit from the rehabilitation due to the absence of units such as cardiology and intensive care in some provinces, high density of the number of patients, priority of urgent

1 Department of Fundamentals, Faculty of Nursing, Sakarya University, Sakarya, Turkey

2 Department of Fundamentals, Faculty of Nursing, Istanbul University, Florance Nightingale, Istanbul, Turkey

Correspondence: Dr. Özlem Dogu, Department of Fundamentals, Faculty of Nursing, Sakarya University, Esentepe Campusu, Serdivan, Sakarya,Turkey

E-mail: ozlemdogu@sakarya.edu.tr

Received: December 27, 2017; Accepted: July 03, 2018 cases, transportation issues and geographical situations. In this case, it is suggested to use web-based training and counselling programmes with phone as an alternative to training in units where rehabilitation is not possible. ${ }^{6-9}$

Developments in information technologies have broadened the boundaries of internet support and made it accessible in everywhere. Internet-supported and web-based distance training is advantageous to reach wide mass, to provide user an interactive, flexible and efficient information environment, to provide health information for both healthy and sick individuals and to contribute to the care of individuals after discharge in chronic health problems. ${ }^{6,9}$ It has been shown through various studies that the use of technology and internet in the training of individuals with some chronic diseases is beneficial. 7,9

Cajandin stated that the planned discharge training and phone counselling is an application that make positive patient outcomes and improved quality of life. ${ }^{4}$ Clark et al. found in their study comparing routine home-based rehabilitation programmes such as web-based training, ${ }^{1}$ tape recordings, phone calls, home visits etc. that there were significant differences between quality of life and risk factors.

In this respect, this research was planned to determine the effect of web-based distance training and counselling on the compliance to treatment, on the functionality and 
well-being of the patients who had myocardial infarction for the first time.

\section{METHODOLOGY}

It was an experimental study with the pretest-posttest repeated measurement and a control group, conducted between 2015 to 2016 in two hospitals in Sakarya in Turkey with individuals who were on MI. For the determination of the number of samples, Turkish Version of Myocardial Infarction Dimensional Assessment Scale (TR-MIDAS): Reliability-Validity Assessment" was taken into consideration. ${ }^{2}$ When the averages were obtained in this study, with the assumption of type 1 error $(\&) 0.05$, second type error $(\alpha) 0.20$, the sample size was calculated both for experiment and control groups as 60 , in a total of 120 individuals who had MI. Assigning the experimental and control groups, sets up method was used.

Randomisation method, which was designed using (http://www1.assumption.edu/users/avadum/applets/Ra ndAssin/Groupgen.html) computer programme, was used to determine whether the individuals meeting the sampling selection criteria be included in the experiment or in the control group. Sample selection criteria were patients with an acute $\mathrm{Ml}$ for the first time, undergone coronary revascularisation or medical treatment, being in stage 1 according to Killip Classification, and having a stable health condition.

In addition to the sampling criteria for the experimentgroup, the general inclusion criteria are having a working computer, internet and phone access at home and being able to use the computer and the web-based remote training programme.

Sampling exclusion criteria were plan of coronary artery bypass grafting and failure to implement the computer and web-based remote training programme.

There were three hypotheses. Hypothesis $1(\mathrm{H} 1)$ was that metabolic control of the individuals, who undergone MI with web-based remote training and counselling, is better compared to the training booklet applied individuals. Hypothesis $2(\mathrm{H} 2)$ was that treatment adaptation for the individuals with web-based remote training and counselling is better compared to the training booklet applied individuals. Hypothesis $3(\mathrm{H} 3)$ was that the level of well-being of the individuals with web-based remote training and counselling is higher compared to the training booklet applied individuals.

Patient Information Form (PIF), MIDAS and Patient Monitoring Form (PMF) were used for data collection. PIF was prepared by the researcher in the light of literature information (age, education, gender etc.). MIDAS, which evaluates the patients' well-being after MI, accordingly, the quality of life, was developed by Thompson et al. and adapted to Turkish language by
Uysal and Özcan. ${ }^{2}$ Including blood glucose, BMI, total cholesterol, LDL, HDL cholesterol, triglyceride parameters, PMF was used in order to evaluate individual's adaptation to the treatment. ${ }^{2}$

MIDAS is a 5-point Likert-type scale consisting of a total of 35 items measured in 7 subscales. The increase in scores indicates that the perceived well-being situation deteriorates. ${ }^{2}$ In this study, the high range of Cronbach alpha values $(0.72-0.94)$ showed that MIDAS total and subscales is a reliable tool for this study.

Using current literature, a training booklet consisting of visual and written texts for the control group, and a webbased distance training programme for the experimental group was prepared by the researcher in parallel with content and scope.10-13 The training contents were presented to nine experts in terms of the conformability before implementation. Using a hosting and domain service, a web page was created on the World Wide Web (www). The page at http://www.kalp.s.....edu.tr/ was placed on the web pages of the hospitals, to facilitate the access of the individuals. The web page titled "After The First Heart Crisis" contains six menus including home page, contents, instructors, application steps, and communication sections.

After the activation with the user name and password defined for each person; in user page, the interface page, which the subject headers and question links are included, is that the active participants can see, and the announcements can be followed up was opened.

The first presentation began with the video "Introduction to Training on Heart Diseases" including brief information on the use of the programme and continued with seven training titles (the structure of heart and MI, drug use, nutrition, physical activity, sexual activity, management of risk factors 1-2) and the completion test consisting of questions prepared by the researcher to evaluate the effectiveness of the study. It was enough to click on the title so that the user could listen to the title of the first topic. Taking adult training and time management into consideration, the presentations were set to take 10-15 minutes.

During the day when the patient would be discharged, PIF, PMF and MIDAS were collected from experimental and control groups. A training booklet was given to the individuals in the control group and the physician control date in the third month was determined in order to get the data belonging to the second follow-up.

The experiment group was informed about the webbased distance training programme on the day they were being discharged. After about 30 minutes of presentation, the individual was asked to watch the first subject in the training programme with researcher.

The experiment group was counselled about drug use, nutrition, physical activity, etc. over the phone until the 
third month after discharge. During this period, the individuals were followed by the researcher in terms of their access to the web page, the duration of the questionnaire, and the length of time the questions were answered.

The data were collected with PMF and MIDAS scale again three months after the discharge from experimental and control groups.

Prior to commencing the study, permission was taken from the Ethics Committee of the Faculty of Medicine of the Sakarya University (29.05.2015/6710). In addition, the individuals, who will constitute the research sample, were informed about the objective, duration of the study and what is expected from them. Their consent was taken to participate in the study in consideration of the willingness and voluntariness policy.

Findings gathered from the study were evaluated by transferring them to the IBM SPSS Statistics 22 software. While the study data were evaluated, it was seen that the numerical variables did not fit the normal distribution. Kolmogorov-Smirnov test was used to evaluate whether the distribution of scales were normal. The scales were presented as the mean \pm standard deviation or median (IQR). Frequency distributions were given for categorical variables, Mann-Whitney U-test was checked for difference between two independent groups. For MIDAS scale's total and sub-dimension reliabilities, the Cronbach's Alpha values and for the difference between two independent categorical variables, Chi-square and McNemar tests were examined. The difference between numerical variables was evaluated by Spearman test and the significance was considered as $p<0.05$.

\section{RESULTS}

The average age of the participants was $54.09 \pm 11.02$ years. They were mostly male, married, literate, had primary school graduate, not working (unemployed and retired), eating mixed diet properly but not exercising and had no training about myocardial infarction. It was determined that the demographic data of the experimental and control groups showed a homogeneous distribution ( $p$-values $=0.159,0.068$, $0.163,0.283,0.067,0.413,0.171,0.083$, and 0.609 respectively, Table I).

There was no statistically significant difference between control and experimental groups in terms of median values of glucose, AST, ALT, total cholesterol, CK-MB, sodium, potassium, BUN, and creatinine $(p=0.071$, $0.420,0.051,0.149,0.138,0.792,0.770,0.457$, and 0.696 , respectively). In terms of median values of triglyceride, LDH, HDL, CRP, calcium and uric acid, there was a statistically significant difference at discharge period $(p<0.001,0.027,0.001,0.005,<0.001$, and 0.019 , respectively).
Three months after the discharge, there was no statistically significant difference found between the control and experimental groups in terms of median values of glucose, AST, total cholesterol, LDL, HDL, CK$\mathrm{MB}$, sodium, potassium, calcium, BUN and creatinine $(p=0.297,0.094,0.347,0.096,0.705,0.952,0.260$, $0.527,0.450,0.385$, and 0.672 , respectively). There was a statistically significant difference found in terms of ALT, triglyceride, CRP and uric acid median values ( $p=0.005$, $<0.001,0.007$, and 0.002 respectively, Table II).

In the third month of discharge, in the control and experimental groups, it was observed that the number of individuals who were obese decreased and but it did not create any statistical difference $(p=0.829$ and 0.349 , respectively) and similarly in groups did not create any statistical difference (respective values were $r=0.113$, $p=0.389$, and $r=0.085-p=0.521$, Table III).

There was no statistically significant difference between the groups in which median values of MIDAS subscale and total score was medium-level in discharger $(p=0.059,0.657,0.466,0.577,0.072,0.376,0.451$, and 0.871 , Table IV).

Three months after the discharge, there were significant differences between control and experimental groups in terms of anxiety of medication, drug side effects, physical activity, insecurity, emotional response, addiction and MIDAS total score median were found in favour of the experimental group (respective p-values were $0.019,0.011,<0.001,<0.001,<0.001,<0.001$, $<0.001)$. In terms of nutrition type sub-score median, there was a significant difference was found in favor of the control group $(p<0.001$, Table IV).

\section{DISCUSSION}

Median values of the designed parameters of the experiment and control groups were observed to begin to fall in both groups due to the compliance of the treatment in first three months after discharge (Table II). After the discharge, it was observed that the control group had better metabolic control (cholesterol and electrolyte values, renal functions) by experiment group; however, the recovery has not continued at the same rate after the 3rd month metabolic control of the experiment group were observed to recover faster $(\mathrm{H} 1)$.

In a similar study conducted by Vernooij et al.,14 after MI, between experimental and control groups were determined that there was no significant difference between the groups in terms of cholesterol, BMI, kidney function and glucose; however, blood values have tended to decrease faster in the experimental group. Lear et al., 15 who applied longer observation have determined that the cholesterol and CRP levels of individuals from experimental group which included web-based distance training and control group which invited to the routine physician control were significantly different in 4th and 10th months. Çevik et al. ${ }^{16}$ stated in 
their study that the health behaviours of the individuals with type 2 diabetes after the training, face-to-face and phone counselling improved, the risk factors were observed to decrease and metabolic control was established; they also emphasised the importance of the counselling as well as the training.

Table I: Distribution of socio-demographic characteristics of individuals $(\mathrm{N}=120)$.

\begin{tabular}{|c|c|c|c|c|c|c|c|c|}
\hline & \multicolumn{2}{|c|}{ Control $(n=60)$} & \multicolumn{2}{|c|}{ Experiment $(n=60)$} & \multicolumn{2}{|c|}{ Total } & \multirow[t]{2}{*}{$\chi^{2}$} & \multirow[t]{2}{*}{$\mathrm{p}$} \\
\hline & $\mathrm{N}$ & $\%$ & $\mathrm{n}$ & $\%$ & $\mathrm{~N}$ & $\%$ & & \\
\hline \multicolumn{9}{|l|}{ Age } \\
\hline $24-39$ & 6 & 10.0 & 3 & 5.0 & 9 & 7.5 & \multirow[t]{4}{*}{$3.649^{*}$} & \multirow[t]{4}{*}{$0.15 \mathrm{~s}$} \\
\hline $40-55$ & 24 & 40.0 & 34 & 56.7 & 58 & 48.3 & & \\
\hline $56+$ & 30 & 50.0 & 23 & 38.3 & 53 & 44.2 & & \\
\hline $\begin{array}{l}X \pm S S \\
(\text { Min-Max) }\end{array}$ & \multicolumn{2}{|c|}{$\begin{array}{c}54.52 \pm 12.98 \\
(24-80)\end{array}$} & \multicolumn{2}{|c|}{$\begin{array}{c}53.67 \pm 8.73 \\
(35-80)\end{array}$} & \multicolumn{2}{|c|}{$\begin{array}{c}54.09 \pm 11.02 \\
(24-80)\end{array}$} & & \\
\hline \multicolumn{9}{|l|}{ Gender } \\
\hline Female & 16 & 26.7 & 8 & 13.3 & 24 & 20.0 & 3.333 & 0.068 \\
\hline Male & 44 & 73.3 & 52 & 86.7 & 96 & 80.0 & & \\
\hline \multicolumn{9}{|l|}{ Marital Status } \\
\hline Married & 53 & 88.3 & 57 & 96.6 & 110 & 92.4 & 2.915 & 0.163 \\
\hline Single & 7 & 11.7 & 2 & 3.4 & 9 & 7.6 & & \\
\hline \multicolumn{9}{|l|}{ Educational background } \\
\hline Literate / primary school & 32 & 53.3 & 25 & 41.7 & 57 & 47.5 & 3.809 & 0.283 \\
\hline Secondary education & 7 & 11.7 & 15 & 25.0 & 22 & 18.3 & & \\
\hline High school & 13 & 21.7 & 12 & 20.0 & 25 & 20.8 & & \\
\hline University & 8 & 13.3 & 8 & 13.3 & 16 & 13.3 & & \\
\hline \multicolumn{9}{|l|}{ Employment status } \\
\hline Yes & 27 & 45.0 & 37 & 61.7 & 64 & 53.3 & 3.348 & 0.067 \\
\hline No & 33 & 55.0 & 23 & 38.3 & 56 & 46.7 & & \\
\hline \multicolumn{9}{|l|}{ Body mass index } \\
\hline Normal & 16 & 26.7 & 10 & 16.7 & 26 & 21.7 & 1.768 & 0.413 \\
\hline Fleshy & 23 & 38.3 & 26 & 43.3 & 49 & 40.8 & & \\
\hline Obese & 21 & 35.0 & 24 & 40.0 & 45 & 37.5 & & \\
\hline $\begin{array}{l}X \pm S S \\
(\text { Min-Max) }\end{array}$ & \multicolumn{2}{|c|}{$\begin{array}{c}28.63 \pm 6.0 \\
(17-49) \\
\end{array}$} & \multicolumn{2}{|c|}{$\begin{array}{c}28.83 \pm 4.34 \\
(19-40)\end{array}$} & \multicolumn{2}{|c|}{$\begin{array}{c}28.73 \pm 5.22 \\
(17-49) \\
\end{array}$} & & \\
\hline Heart disease story in famil & & & & & & & & \\
\hline Yes & 33 & 55.0 & 26 & 44.1 & 59 & 49.6 & 1.422 & 0.233 \\
\hline No & 27 & 45.0 & 33 & 55.9 & 60 & 50.4 & & \\
\hline Chronic disease & & & & & & & & \\
\hline Yes & 27 & 45.0 & 22 & 36.7 & 49 & 40.8 & 0.862 & 0.353 \\
\hline No & 33 & 55.0 & 38 & 63.3 & 71 & 59.2 & & \\
\hline Nutrition habit & & & & & & & & \\
\hline Regular & 45 & 75.0 & 51 & 85.0 & 96 & 80.0 & 1.875 & 0.171 \\
\hline Irregular & 15 & 25.0 & 9 & 15.0 & 24 & 20.0 & & \\
\hline Smoking & & & & & & & & \\
\hline Yes & 32 & 53.3 & 36 & 60.0 & 68 & 56.7 & 5.735 & 0.057 \\
\hline No & 25 & 41.7 & 15 & 25.0 & 40 & 33.3 & & \\
\hline Quitted & 3 & 5.0 & 9 & 15.0 & 12 & 10.0 & & \\
\hline Alcohol use & & & & & & & & \\
\hline Yes & 11 & 18.3 & 7 & 11.7 & 18 & 15.0 & $1.356^{*}$ & 0.508 \\
\hline No & 46 & 76.7 & 51 & 85.0 & 97 & 80.8 & & \\
\hline Left & 3 & 5.0 & 2 & 3.3 & 5 & 4.2 & & \\
\hline Regular exercise & & & & & & & & \\
\hline Yes & 25 & 41.7 & 16 & 26.7 & 41 & 34.2 & 3.001 & 0.083 \\
\hline No & 35 & 58.3 & 44 & 73.3 & 79 & 65.8 & & \\
\hline Previously receiving trainin & & & & & & & & \\
\hline Yes & 10 & 16.7 & 8 & 13.3 & 18 & 15.0 & 0.261 & 0.609 \\
\hline No & 50 & 83.3 & 52 & 86.7 & 102 & 85.0 & & \\
\hline Duration of stay in hospital & & & & & & & & \\
\hline $\mathrm{X} \pm \mathrm{SS}$ & & & & & & & 3.251 & 0.144 \\
\hline (Min-Max) & & & & & & & & \\
\hline
\end{tabular}

*:Likelihood ratio. 
The findings of the present study are in parallel with the literature as well as demonstrating once again the importance of the training for the conformity of the individuals in both groups. $17-19$

While the control and experimental groups showed a numerical difference in their BMI values at the admission and the third month after discharge, this difference was not significant (Table III). The importance of obesity in reducing the risk of $\mathrm{Ml}$ is emphasised with the necessity of strengthening individual through training and behavior changes in nutrition and physical activity.4,13,20,21 For this reason, the decrease of BMI in both groups was encouraging, and suggesting that it requires a longer follow-up.

Similar to this study, Zutz et al., 6 who used web-based training and mobile counselling, found in their study that lipid values, exercise capacity and BMI improved positively compared to the control group, Dunn et al.22 stated that at the end of the 15-week training programme, average weight loss of the experimental group using the web-based distance training was 3.65 $\mathrm{kg}$ and control group receiving face-to-face training had $2.7 \mathrm{~kg}$. It was also seen that there was no significant difference between groups in terms of nutrition and

Table II: Comparison of blood values of individuals at discharge and 3 months after discharge $(\mathrm{N}=120)$.

\begin{tabular}{|c|c|c|c|c|c|c|}
\hline & \multicolumn{2}{|c|}{ Discharge } & \multirow[b]{2}{*}{$z ; p$} & \multicolumn{2}{|c|}{3 months after discharge } & \multirow[b]{2}{*}{$Z ; p$} \\
\hline & $\begin{array}{c}\text { Control group } \\
\text { Median-IQR (Min-Max) }\end{array}$ & $\begin{array}{c}\text { Experiment group } \\
\text { Median-IQR (Min-Max) }\end{array}$ & & $\begin{array}{c}\text { Control group } \\
\text { Median-IQR (Min-Max) }\end{array}$ & $\begin{array}{c}\text { Experiment group } \\
\text { Median-IQR (Min-Max) }\end{array}$ & \\
\hline Glucose & $123.00-64.5(80-420)$ & $110.00-30.0(80-310)$ & $-1.808 ; 0.071$ & $114.50-331.5(86-222)$ & $110.00-23.0(88-230)$ & $-1.042 ; 0.297$ \\
\hline AST & $30.50-18.0(0-92)$ & $32.00-26.5(9-91)$ & $-0.806 ; 0.420$ & $25.0015 .5(11-59)$ & $27.00-19.0(13-79)$ & $-1.674 ; 0.094$ \\
\hline ALT & $24.50-24.5(0-66)$ & $29.00-31.0(11-91)$ & $-1.954 ; 0.051$ & $24.0022 .5(10-59)$ & $31.00-31.5(11-91)$ & $-2.778 ; 0.005^{\star}$ \\
\hline TC & $200.00-54.5(120-320)$ & $199.00-38.5(100-400)$ & $-1.442 ; 0.149$ & $140.00-57.0(98-245)$ & $145.00-68.0(96-280)$ & $-0.941 ; 0.347$ \\
\hline Triglyceride & $76.50-56.0(38-380)$ & $132.00-94.5(36-590)$ & $-4.904 ; 0.000^{*}$ & $80.00-40.0(38-210)$ & $104.00-50.0(55-240)$ & $-4.360 ;<0.001^{*}$ \\
\hline$\underline{\text { LDL }}$ & $100.00-30.0(55-218)$ & $115.00-42.5(62-250)$ & $-2.208 ; 0.027^{*}$ & $89.00-30.5(45-166)$ & $99.50-21.0(36-150)$ & $-1.665 ; 0.096$ \\
\hline $\mathrm{HDL}$ & $44.00-8.2(32-70)$ & $37.00-13.0(22-65)$ & $-3.274 ; 0.001^{*}$ & $52.0014 .1(28-65)$ & $55.00-16.0(30-88)$ & $-0.379 ; 0.705$ \\
\hline CK-MB & $36.80-53.7(8-226)$ & $29.40-16.7(10-329)$ & $-1.483 ; 0.138$ & $22.00-24.1(0-128)$ & $22.00-13.5(0-70)$ & $-0.060 ; 0.952$ \\
\hline CRP & $6.00-5.0(1-17)$ & $8.00-12.9(1-131)$ & $-2.781 ; 0.005^{*}$ & $4.003 .9(0-14)$ & $5.77-5.2(1-25)$ & $-2.697 ; 0.007^{\star}$ \\
\hline Sodium & $138.00-7.0(122-146)$ & $138.00-4.0(124-143)$ & $-0.264 ; 0.792$ & $135.00-6.0(122-143)$ & $133.50-7.5(120-144)$ & $-1.126 ; 0.260$ \\
\hline Potassium & $4.35-0.7(4-10)$ & $4.50-0.7(4-5)$ & $-0.292 ; 0.770$ & $4.20-0.7(4-5)$ & $4.60-1.0(4-6)$ & $-0.633 ; 0.527$ \\
\hline Calcium & $8.70-1.0(7-10)$ & $9.10-0.8(7-10)$ & $-3.592 ; 0.000^{*}$ & $8.55-1.0(7-10)$ & $8.65-1.1(7-10)$ & $-0.755 ; 0.450$ \\
\hline BUN & $19.50-6.0(7-33)$ & $20.00-13.0(8-32)$ & $-0.744 ; 0.457$ & $18.00-6.0(8-33)$ & $16.50-8.5(7-32)$ & $-0.868 ; 0.385$ \\
\hline Uric acid & $5.10-1.8(3-10)$ & $5.70-2.0(4-8)$ & $-2.337 ; 0.019^{*}$ & $5.00-1.7(3-10)$ & $5.70-1.6(4-10)$ & $-3.067 ; 0.002^{*}$ \\
\hline Creatinine & $0.95-0.3(1-8)$ & $0.86-0.2(1-8)$ & $-0.391 ; 0.696$ & $0.92-0.2(1-8)$ & $0.89-0.2(1-8)$ & $-0.423 ; 0.672$ \\
\hline
\end{tabular}

Descriptive statistics were shown as medium (IQR) . ${ }^{*}$ p: Nonparametric test results (Mann-Whitney U).

Table III: Comparison of body mass index averages of individuals at discharge and 3 months after discharge $(\mathrm{N}=120)$.

\begin{tabular}{|c|c|c|c|c|c|c|c|c|c|c|c|c|}
\hline & \multicolumn{6}{|c|}{ Control group $(n=60)$} & \multicolumn{6}{|c|}{ Experiment group $(n=60)$} \\
\hline & \multicolumn{2}{|c|}{ Discharge } & \multicolumn{2}{|c|}{$\begin{array}{c}3 \text { months after } \\
\text { discharge }\end{array}$} & \multirow[t]{2}{*}{ McNemar } & \multirow[t]{2}{*}{$\mathrm{p}$} & \multicolumn{2}{|c|}{ Discharge } & \multicolumn{2}{|c|}{$\begin{array}{l}3 \text { months after } \\
\text { discharge }\end{array}$} & \multirow[t]{2}{*}{ McNemar } & \multirow[t]{2}{*}{$\mathrm{p}$} \\
\hline & $\mathrm{n}$ & $\%$ & $\mathrm{n}$ & $\%$ & & & $\mathrm{n}$ & $\%$ & $\mathrm{n}$ & $\%$ & & \\
\hline Normal+ & 16 & 26.7 & 20 & 33.3 & 0.885 & $0.829^{*}$ & 10 & 16.7 & 17 & 28.3 & 3.292 & $0.349^{*}$ \\
\hline Fleshy++ & 23 & 38.3 & 22 & 36.7 & & & 26 & 43.3 & 26 & 43.3 & & \\
\hline Obese+++ & 21 & 35.0 & 18 & 30.0 & & & 24 & 40.0 & 17 & 28.3 & & \\
\hline
\end{tabular}

BMl kg/m $\quad r=0.063 p=0.631^{* *} \quad r=0.216 p=0.098^{\text {** }}$

${ }^{*} p:$ McNemar ${ }^{* *} r$ : Spearman's correaltion coefficient. p-values of the statistically significant correlation coefficients were shown as bold.+ Normal : $18-24.9++$ Fleshy: $25-29.9+++$ Obese: 30 and above.

Table IV: Comparison of MIDAS points of individuals at discharge and 3 months after discharge $(\mathrm{N}=120)$.

\begin{tabular}{|c|c|c|c|c|c|c|}
\hline & \multicolumn{2}{|c|}{ Discharge } & \multirow[b]{2}{*}{$Z ; p$} & \multicolumn{2}{|c|}{3 months after discharge } & \multirow[b]{2}{*}{$Z ; p$} \\
\hline & $\begin{array}{l}\text { Control group } \\
\text { Median-IQR }\end{array}$ & $\begin{array}{c}\text { Experiment group } \\
\text { Median-IQR }\end{array}$ & & $\begin{array}{c}\text { Control group } \\
\text { Median-IQR }\end{array}$ & $\begin{array}{c}\text { Experiment group } \\
\text { Median-IQR }\end{array}$ & \\
\hline Physical activity sub-dimension & $31.25-27.1$ & 20.83-40.6 & $-1.891 ; 0.059$ & $25.00-16.7$ & $2.08-10.4$ & $-6.650 ;<0.001^{*}$ \\
\hline Insecurity sub-dimension & 23.61-38.9 & 19.44-33.3 & $-0.444 ; 0.657$ & $25.00-27.8$ & $8.33-15.3$ & $-6.305 ;<0.001^{*}$ \\
\hline Emotional response sub-dimension & $34.38-37.5$ & $37.50-31.3$ & $-0.729 ; 0.466$ & $25.00-40.6$ & $0.00-3.1$ & $-6.447 ;<0.001^{*}$ \\
\hline Addiction sub-dimension & 33.33-33.3 & $41.67-25.0$ & $-0.558 ; 0.577$ & 41.67-29.2 & $12.50-33.3$ & $-4.601 ;<0.001^{*}$ \\
\hline Nutrition type sub-dimension & $50.00-29.2$ & $54.17-41.7$ & $-1.796 ; 0.072$ & $50.00-41.7$ & $75.00-29.2$ & $-4.349 ;<0.001^{*}$ \\
\hline Anxiety about drug sub-dimension & $43.75-62.5$ & $43.75-50.0$ & $-0.885 ; 0.376$ & $37.50-25.0$ & $25.00-37.5$ & $-2.339 ; 0.019^{*}$ \\
\hline Drug side effects sub-dimension & $0.00-25.0$ & $0.00-31.3$ & $-0.754 ; 0.451$ & $25.00-37.5$ & $0.00-18.8$ & $-2.544 ; 0.011^{*}$ \\
\hline MIDAS total & $30.00-24.3$ & $26.43-22.1$ & $-0.163 ; 0.871$ & 28.57-16.1 & 13.57-11.8 & $-6.075 ;<0.001^{*}$ \\
\hline
\end{tabular}

Descriptive statistics were shown as medium (IQR) . ${ }^{*} p$ : Nonparametric test results (Mann-Whitney $U$ ) 
physical activity. However the weight loss had created low-level significance. The fact that these findings reject the $\mathrm{H} 2$ hypothesis reveals the effect of training once more. In addition, it was observed that patients have been importance of follow long-term after the discharge.

When the MIDAS median scores are analysed, the total MIDAS score medians of both groups were at medium values as 30.00 and 26.43 . It shows similarity to the findings of Devi et al. and Koh et al. and reveals the Ml's negative effect on the quality of life of the individual. 3,7 In the third month after discharge, it was seen that there was a significant difference in favour of the experiment group in terms of MIDAS median (Table IV).

In the literature, it is emphasised that mobile and webbased training after MI has a positive effect on the quality of life. $1,4,7,12,21,23$ Considering that the average age of the participating individuals and the level of education in the majority were low, the use of web-based remote training and the decreasing MIDAS median scores were evaluated as a positive situation and showed that counselling and training were supported (H3).

Maddison et al. applied that have been informed and reminded with mobile support for six months, and have also provided training on web about risk factors, and they have routinely applied to the control group. They stated that positive effects on quality of life, management of risk factors. ${ }^{23}$

Similary, Younge et al. found that participants were significantly different in exercise capacity after three months of follow-up in cardiac patients, there was no significant difference in the quality of life and some physiological parameters; but there was a positive effect, and it was suggested that it can be used as addition to treatment.24

Web-based training can be primarily preferred for postMI training by providing individuals with 24-hour day-today information and support without problems such as time and space, creating health-related behavioural changes in health, and providing a highly interactive learning environment for individuals.14,15,25 This and other study shows that using web-based distance technology and counselling can help patient contributing, and positive effective for well-being and compliance.

\section{CONCLUSION}

Web-based distance learning and counselling have positive effects on individuals with myocardial infarction, in treatment compliance, in acquiring health behaviours, in improving their well-being, and thus their quality of life. It may be advised to use them as an alternative to traditional training practices in the form of booklets, especially for the individuals who could not participate in cardiac rehabilitation and for the individuals who could not use the computer or have no internet connection. It may be advised to conduct studies which will include longer duration of follow-up.

Acknowledgement: This study was supported by the Istanbul Universty Scientific Research Projects (BAP) (Project No: 55703).

\section{REFERENCES}

1. Clark AM, Haykowsky M, Kryworuchko J, MacClure T, Scott J, DesMeules $\mathrm{M}$. et al. A meta-analysis of randomized control trials of home-based secondary prevention programs for coronary artery disease. Eur J Cardiovasc Prevent Rehabil 2010; 17:261-70.

2. Uysal H, Özcan S. A Turkish version of myocardial infarction dimensional assessment scale (TR-MIDAS): Reliability-validity assesment. Eur J Cardiovascr Nurs 2011; 10:15-23.

3. Koh KWL, Wang W, Richards AM, Chan MY, Cheng KKF. Effectiveness of advanced practice nurse-led telehealth on readmissions and health-related outcomes among patients with postacute myocardial infarction: ALTRA Study Protocol. J Adv Nurs 2016;72:1357-67.

4. Cajanding RJ. Effects of a structured discharge planning program on perceived functional status, cardiac self-efficacy, patient satisfaction, and unexpected hospital revisits among Filipino cardiac patients: A randomized controlled study. J Cardiovasc Nurs 2017; 32:67-77.

5. Zahid S, Mehmood Gul A, Sohail Taj H, Sharif MH, Ayaz T. Association of knowledge, attitude and behavioural risk factors with coronary artery disease. Pak Heart J 2016; 49:61-5.

6. Zutz A, Ignaszewski A, Bates J, Lear SA. Utilization of the Internet to deliver cardiac rehabilitation at a distance: A pilot study. Telemed e-Health 2007; 13:323-30.

7. Devi R, Powel J, Singh S. A web-based program improves physical activity outcomes ina primary care angina population: Randomized controlled trial. J Med Internet Res 2014; 16:1-13.

8. Devi R, Singh SJ, Powell J, Fulton EA, Igbinedion E, Rees K. Internet-based interventions for the secondary prevention of coronary heart disease. Cochrane Libr 2015; 12:1-80.

9. Dogu Ö, Kaya H, Gündüz H, Parlak Z. Web based distance learning suggestion in training and consultation for myocardial infarction patients. MN Kardiyoloji 2015; 22:217-22.

10. European Society Of Cardiology. Avrupa klinik uygulamada kardiyovasküler hastaliklardan korunma kilavuzu. Türk Kardiyol Dern Ars 2012; 3:4-62.

11. American Association of Cardiyovascular and Pulmoner Rehabilitation (AACVPR). Guidelines for Cardiac Rehabilitation and Secondary Prevention Programs 5th Edition With Web Resource: 2013;1-363.

12. Munro J, Angus N, Leslie SJ. Patient focused Internet-based approaches to cardiovascular rehabilitation - a systematic review. J Telemed Telecare 2013; 19:347-53.

13. Fontaine G, Cossette S, Heppell S, Boyer L, Mailhot T, Simard MJ, et al. Evaluation of a web-based e-learning platform for brief motivational interviewing by nurses in cardiovascular care: A pilot study. J Med Internet Res 2016; 18:11-7.

14. Vernooij JW, Kaasjager HA, Graaf Y, Wierdsma J, Grandjean $\mathrm{HM}$, Hovens MM, et al. Internet-based vascularrisk factor 
management for patients with clinically manifestvascular disease: randomised controlled trial. BMJ 2012; 344:1-13.

15. Lear SA, Singer J, Banner-Lukaris D, Horvat D, Park JE, Bates J, et al. Randomized trial of a virtual cardiac rehabilitation program delivered at a distance via the internet. Clin Trial Regist 2014; 7:952-9.

16. Bayindir Çevik A, Özcan S, Satmanl. Reducing the modifiable risks of cardiovascular disease in Turkish patients with type 2 diabetes: The effectiveness of training. Clin Nurs Res 2015; 24:299-317.

17. Kamaty DY, Xavier D, Gupta R, Devereaux PJ, Sigamani A, Hussain $\mathrm{T}$, et al. Rationale and design of a randomized controlled trial evaluating community health worker (CHW) based interventions for the secondary prevention of acute coronary syndromes in India (SPREAD). Am Heart J 2014; 168:690-7.

18. Andjic M, Spiroski D, llic SO, Vidakovic T, Lazovic M, Babic D, et al. Effect of short-term exercise training in patients following acute myocardial infarction treated with primary percutaneous coronary intervention. Eur J Phys Rehabil Med 2016; 52:364-9.

19. Heron N, Kee F, Donnelly M, Tully MA, Cupples ME. Systematic review of the use of behaviour change techniques (BCTs) in home-based cardiac rehabilitation programmes for patients with cardiovascular disease-protocol. BioMed Central Systematic Rev 2015; 4:2-5.

20. Wood DA, Kotseva K, Connolly S, Jennings C, Mead A, Jones J, et al. Nurse-coordinated multidisciplinary, family-based cardiovascular disease prevention programme (EUROACTION) for patients with coronary heart disease and asymptomatic individuals at high risk of cardiovascular disease: a paired, cluster-randomised controlled trial. Lancet 2012; 371:19992012.

21. Kirchberger I, Hunger M, Stollenwerk B, Seidl H, Burkhardt K, Kuch $\mathrm{B}$, et al. Effects of a 3-year nurse-based case management in aged patients with acute myocardial infarction on rehospitalisation, mortality, risk factors, physical functioning and mental health. A secondary analysis of the randomized controlled KORINNA study. PLoS One 2015; 10: 1-17.

22. Dunn C, Olabode-Dada O, Whetstone L, Thomas C, Aggarwal S, Nordby $\mathrm{K}$, et al. Using synchronous distance education to deliver a weight loss intervention: A randomized trial. Obesity 2016; 24:44-50.

23. Maddison R, Pfaeffli L, Whittaker R, Stewart R, Kerr A, Jiang $Y$, et al. A mobile phone intervention increases physical activity in people with cardiovascular disease: Results from the HEART randomized controlled trial. Eur J Prevent Cardiol 2015; 22: 701-9.

24. Younge YO, Wery MF, Gotink RA, Utens EM, Michels M, Rizopoulos $D$, et al. Web-based mind fulness intervention in heart disease: A randomized controlled trial. PLoS One 2015; 10:1-19.

25. Antypas K, Wangberg SC. Internet- and mobile-based tailored intervention to enhance maintenance of physical activity after cardiac rehabilitation: Short-term results of a randomized controlled trial. J Med Internet Res 2014; 16:77. 